\title{
BMJ Open How smoking affects the proportion of deaths attributable to obesity: assessing the role of relative risks and weight distributions
}

\author{
Andrew Stokes, ${ }^{1}$ Samuel H Preston ${ }^{2}$
}

To cite: Stokes A, Preston SH. How smoking affects the proportion of deaths attributable to obesity: assessing the role of relative risks and weight distributions. BMJ Open 2016;6:e009232. doi:10.1136/bmjopen-2015009232

- Prepublication history and additional material is available. To view please visit the journal (http://dx.doi.org/ 10.1136/bmjopen-2015009232).

Received 29 June 2015 Revised 10 December 2015 Accepted 16 December 2015

\section{CrossMark}

${ }^{1}$ Department of Global Health and Center for Global Health and Development, Boston University School of Public Health, Boston, Massachusetts, USA

${ }^{2}$ Department of Sociology and Population Studies Center, University of Pennsylvania, Philadelphia, Pennsylvania, USA

Correspondence to Dr Andrew Stokes; acstokes@bu.edu

\section{ABSTRACT}

Objective: Although ever-smokers make up the majority of the older adult population in the USA, they are often excluded from studies examining the impact of obesity on mortality. Understanding how smoking and obesity interact is critical to assessing the proportion of deaths attributable to obesity.

Setting: Nationally representative sample of the noninstitutionalised population of the USA. Baseline data were drawn from the National Health and Nutrition Examination Survey, 1988-1994 and 1999-2004.

Participants: US adults aged $50-74(\mathrm{n}=9835)$. Primary outcome measure: We used Cox models to estimate the mortality risks of obesity by smoking status. All-cause mortality was assessed prospectively through 31 December 2006 ( $n=1243$ deaths).

Maximum body mass index (BMI) was specified as the key exposure variable. We also calculated population attributable fractions (PAFs) by smoking status and investigated differences in PAFs in a decomposition analysis.

Results: The HR associated with a one-unit increment in BMI beyond $25.0 \mathrm{~kg} / \mathrm{m}^{2}$ was 1.057 for neversmokers $(95 \% \mathrm{Cl} 1.033$ to $1.082 ; p<0.001), 1.036$ for former smokers $(95 \% \mathrm{Cl} 1.015$ to $1.059 ; p<0.01)$ and 1.024 for current smokers $(95 \% \mathrm{Cl} 0.997$ to 1.052$)$.

We estimated that $19.8 \%$ of deaths were attributable to excess weight. The PAFs were 31.9, 20.4 and 11.3 for never-smokers, former and current smokers, respectively. The difference in PAFs between neversmokers and current smokers was almost entirely explained by the difference in HRs.

Conclusions: The proportion of deaths attributable to obesity is nearly 3 times as high among neversmokers compared with current smokers. This finding is consistent with the fact that smokers are subject to significant competing risks. Analyses that exclude smokers are likely to substantially overestimate the proportion of deaths attributable to obesity in the USA.

\section{INTRODUCTION}

Smoking and obesity are leading causes of premature mortality in the USA. ${ }^{1}$ How these

\section{Strengths and limitations of this study}

- Using high-quality nationally representative data this study considers in greater detail than previous studies how two leading causes of premature mortality in the USA interact.

- We use a novel indicator of obesity, an individual's maximum body mass index, which pertains to the life cycle rather than simply to baseline circumstances.

- Compared with body mass index measured at the time of survey, maximum body mass index is less affected by reverse causality-a major source of bias in observational studies of the association between obesity and mortality.

- In contrast to many studies, we do not exclude major subgroups from the attributable risk calculation, so that it pertains to the population as a whole, including sick people and smokers.

- A limitation of the study is that maximum body mass index is self-reported and may be subject to measurement error.

risk factors interact has not been thoroughly investigated. In this paper, we focus on the impact of smoking on the proportion of deaths attributable to obesity in the contemporary USA.

The mortality risks of obesity are often estimated after eliminating ever-smokers and people with chronic conditions from the sample and assuming that the estimated risks for never-smokers and healthy people apply to the entire population. ${ }^{2-4}$ These restrictions generally strengthen associations between obesity and mortality, in some cases greatly. However, the restrictions can exclude up to $80 \%$ of deaths, leading some researchers to question the external validity of the results. ${ }^{5}$

Proponents of strict exclusion criteria argue that such measures are necessary for obtaining valid estimates of the mortality risks of obesity. ${ }^{6}$ Smoking is thought to be so 
strongly related to obesity and mortality that it is difficult to avoid residual confounding even when using typical adjustments for smoking status and intensity. However, by removing smokers, a major source of risk that competes with obesity is removed, leading to the false impression that obesity is associated with a larger relative burden than it is. ${ }^{7} 8$

Smokers may have a lower proportion of deaths attributable to obesity than non-smokers for two reasons. First, smoking changes the body mass index (BMI) distribution of the population. Many smokers lose weight, or fail to gain weight, because of smoking. A review of epidemiological and biomedical studies of the effect of smoking on weight suggests that US smokers weigh, on average, 4-5 kg less than non-smokers. ${ }^{9}$ When smokers quit, they gain, on average, $4.5 \mathrm{~kg}$ within 6-12 months after quitting, and their weight returns to the same weight trajectory over age as that observed in nonsmokers. Smoking increases $24 \mathrm{~h}$ energy expenditure by about $10 \%$. Nicotine's effects on the brain also leads to suppression of appetite, and smoking per se can serve as a behavioural alternative to eating.

A second reason why smokers may have a lower fraction of deaths attributable to obesity than non-smokers is that the relative risks of death associated with obesity may be lower among smokers. When one major exposure is added to the environment in which another exposure is operative, a high fraction of deaths may be caused by the additional exposure, reducing the fraction of deaths that remain to be 'caused' by the original exposure.

Whether the mortality risks associated with obesity are different for smokers and non-smokers has been investigated in four large American cohort studies ranging from 78000 to 1.2 million participants. All found that the risk of death associated with obesity was greater among non-smokers or never-smokers than among current smokers or ever-smokers. ${ }^{10-13}$ The Prospective Studies Collaboration pooled data on the mortality risks of obesity from 57 studies including 895000 participants. ${ }^{14}$ This study concluded that the excess risks for BMI and smoking were 'roughly additive' rather than multiplicative. They demonstrate that the death rate, when graphed as a function of linear BMI, was displaced upwards by a nearly constant amount for smokers relative to non-smokers above the minimum-risk BMI interval of $22.5-25 \mathrm{~kg} / \mathrm{m}^{2}$. Such a displacement implies a lower relative risk of death associated with obesity for smokers than for non-smokers (see online supplementary appendix 1 , which develops an additive model of relations between two exposures).

This paper builds on this literature by providing estimates of the proportion of deaths attributable to obesity for the entire population of the USA and for population subgroups distinguished by smoking status. We use a summary measure of weight history, the maximum weight an individual has achieved, in constructing our exposure variable. ${ }^{15}{ }^{16}$ Relative to baseline
BMI, maximum weight may better capture potential cumulative effects of past obesity status and has the advantage of being less affected by reverse causality, the downward bias in the estimated mortality effects of obesity that results from weight loss among those who are seriously ill.

\section{METHODS}

The data for this analysis were drawn from the National Health and Nutrition Examination Survey (NHANES). We combined the NHANES III (1988-1994) ${ }^{17}$ and continuous NHANES cohorts (1999-2004) ${ }^{18}$ and linked these to mortality status in the National Death Index through 2006. ${ }^{19}$ NHANES is a nationally representative survey of the non-institutionalised population of the USA that combines interviews and clinical measurement. A unique feature of NHANES is that it asks questions about weight histories, including an individual's maximum weight (exclusive of weight during pregnancy). This information, along with height measured at the time of survey, was used to construct the key exposure variable in our analysis, maximum BMI. This variable was chosen to represent the effects of BMI as a cumulative process ${ }^{20} 21$ and to minimise the effect of reverse causation, which biases downwards the estimated relative risk of death from obesity. ${ }^{15}{ }^{22}$ This effect is expected to be especially powerful among smokers because of the high incidence of illness and death in that group.

Cox models were used to investigate the mortality risks of obesity among individuals aged 50-74. We began with a relatively older age in order that individuals have accumulated substantial weight trajectories that can be suitably summarised by maximum BMI. Observations after individuals reach age 75 were censored. The parameters of hazards models were estimated separately for the three smoking groups. We distinguished those who never smoked (defined as having smoked fewer than 100 cigarettes in one's lifetime), those who currently smoke, and those who formerly smoked but who have quit.

The key independent variable in the analysis, maximum BMI, was specified as units of BMI above 25 . Using this variable linearly in a hazard model implies that risks increase exponentially above a BMI of 25 (ie, they increase linearly in the $\log$ of the hazard). Strong empirical support for such a shape emerged from the Prospective Studies Collaboration. ${ }^{14}$ Those in the BMI range of 18.5-24.9 were assigned a value of 0 on this measure and those with BMIs below 18.5 were dropped from the analysis (nine observations). In a preliminary analysis, we tested quadratic models to investigate nonlinearities in the relation between BMI and the $\log$ of mortality. Coefficients on the quadratic terms were insignificant and thus dropped in subsequent modelling.

The Cox models were adjusted for sex, age, race/ethnicity (Hispanics, black non-Hispanic and other), and 
educational attainment (less than high school graduate, high school graduate and more than high school). For current and former smokers, we additionally adjusted for smoking intensity using the following categories: $<1$, 1-2, 2 or more packs/day. Smoking intensity for former smokers was determined based on a question that asked about the number of cigarettes smoked per day at the time of quitting.

The proportion of deaths attributable to obesity (population attributable fraction (PAF)) was calculated as the weighted average of PAFs in different strata, with the appropriate weights being the number of deaths in the various strata. ${ }^{23}$ The formula used to assess the PAF within each smoking category is the following:

$$
\mathrm{PAF}=\sum_{\mathrm{i}=0}^{\mathrm{K}} \operatorname{pd}_{\mathrm{i}}\left(\frac{\mathrm{HR}_{\mathrm{i}}-1}{\mathrm{HR}_{\mathrm{i}}}\right)
$$

where $\mathrm{pd}_{\mathrm{i}}$ refers to the proportion of decedents in BMI category $i$ and $H_{R}$ refers to the $\mathrm{HR}$ with respect to mortality for an individual in category i. Individuals in the normal weight category were assigned a HR of 1.0.
The HRs used in this analysis are derived from multivariate Cox models. To apply equation (1), we use three-unit wide BMI intervals beyond 25 and employ the HR predicted for the mid-point of each interval. The BMI distribution for the different smoking groups can be found in online supplementary appendix 2. While we describe the results of applying equation (1) as providing estimates of the proportion of deaths attributable to obesity, it is most precisely described as the proportion of deaths attributable to having a BMI above 25.0, a range that includes overweight individuals.

We used a two-step process to attribute the difference in PAFs between current smokers and never-smokers to differences in BMI distributions versus differences in the mortality risks of obesity. The approach is based on equation (1). To estimate how much of the difference in PAFs between current smokers and never-smokers is caused by differences in their BMI distributions, we recalculated the PAF combining the HRs of neversmokers with the BMI distribution of current smokers to produce a hypothetical distribution of deaths by BMI status. This process produces an estimate of what the PAF would be for never-smokers if they maintained their

Table 1 Characteristics of US adults ages $50-74$ by smoking status

\begin{tabular}{|c|c|c|c|c|c|c|}
\hline & \multicolumn{2}{|c|}{$\begin{array}{l}\text { Never-smokers } \\
(n=4159)\end{array}$} & \multicolumn{2}{|c|}{$\begin{array}{l}\text { Former smokers } \\
(\mathrm{n}=3601)\end{array}$} & \multicolumn{2}{|c|}{$\begin{array}{l}\text { Current smokers } \\
(n=2075)\end{array}$} \\
\hline & $\mathbf{N}$ & $\begin{array}{l}\text { Percentage } \\
\text { or mean }\end{array}$ & $\mathbf{N}$ & $\begin{array}{l}\text { Percentage } \\
\text { or mean }\end{array}$ & $\mathbf{N}$ & $\begin{array}{l}\text { Percentage } \\
\text { or mean }\end{array}$ \\
\hline Deceased & 307 & 5.4 & 463 & 10.0 & 473 & 19.1 \\
\hline Age at survey, years & & 60.7 & & 61.4 & & 58.8 \\
\hline Female & 2807 & 67.1 & 1281 & 39.4 & 874 & 47.4 \\
\hline \multicolumn{7}{|l|}{ Education } \\
\hline Less than high school & 1756 & 25.1 & 1432 & 25.0 & 1028 & 34.7 \\
\hline $\begin{array}{l}\text { High school or } \\
\text { equivalent }\end{array}$ & 1053 & 28.9 & 905 & 28.9 & 550 & 32.5 \\
\hline More than high school & 1350 & 46.0 & 1264 & 46.1 & 497 & 32.8 \\
\hline \multicolumn{7}{|l|}{ Race/ethnicity } \\
\hline Hispanic & 1206 & 9.4 & 827 & 6.2 & 446 & 7.1 \\
\hline Non-Hispanic black & 886 & 9.6 & 659 & 6.9 & 613 & 12.6 \\
\hline Other & 2067 & 81.0 & 2115 & 86.9 & 1016 & 80.3 \\
\hline BMI, maximum $\left(\mathrm{kg} / \mathrm{m}^{2}\right)$ & & 30.4 & & 30.8 & & 29.4 \\
\hline \multicolumn{7}{|l|}{ Obesity status at maximum } \\
\hline Normal & 621 & 18.9 & 393 & 12.8 & 441 & 23.2 \\
\hline Overweight & 1469 & 36.1 & 1344 & 38.6 & 779 & 36.4 \\
\hline Obese class I & 1196 & 26.2 & 1119 & 29.7 & 561 & 27.2 \\
\hline Obese class II & 873 & 18.8 & 745 & 18.9 & 294 & 13.2 \\
\hline Age at maximum BMI & & 51.3 & & 51.9 & & 46.6 \\
\hline \multicolumn{7}{|c|}{ Smoking intensity (packs/day) } \\
\hline 0 to $<1$ & & & 1448 & 36.3 & 934 & 35.0 \\
\hline 1 to $<2$ & & & 1241 & 36.3 & 804 & 45.4 \\
\hline$>2$ & & & 711 & 22.4 & 206 & 14.4 \\
\hline Missing & & & 201 & 5.1 & 131 & 5.2 \\
\hline \multicolumn{7}{|c|}{$\begin{array}{l}\text { Categories of BMl are normal weight }\left(18.5-24.9 \mathrm{~kg} / \mathrm{m}^{2}\right) \text {; overweight }\left(25.0-29.9 \mathrm{~kg} / \mathrm{m}^{2}\right) \text {; obese class } 1\left(30.0-34.9 \mathrm{~kg} / \mathrm{m}^{2}\right) \text {; and obese class } 2 \\
\left(35.0 \mathrm{~kg} / \mathrm{m}^{2} \text { or greater). Never-smokers are defined as those having smoked less than } 100 \text { cigarettes in their lifetime. The characteristics }\right. \\
\text { pertain to persons aged } 50-74 \text {, surveyed in years } 1988-2004 \text { with mortality follow-up through } 2006 \text {. Age at maximum BMI is calculated } \\
\text { using data from the NHANES continuous waves only as this question was not asked in the NHANES III. Estimates of means and } \\
\text { percentages incorporate NHANES sample weights. Sources: NHANES. } \\
\text { BMI, body mass index; NHANES, National Health and Nutrition Examination Survey. }\end{array}$} \\
\hline
\end{tabular}


Figure 1 Components of the population attributable fraction: (A) body mass index distribution in the deaths (\%) and (B) HRs for mortality from all causes.
A

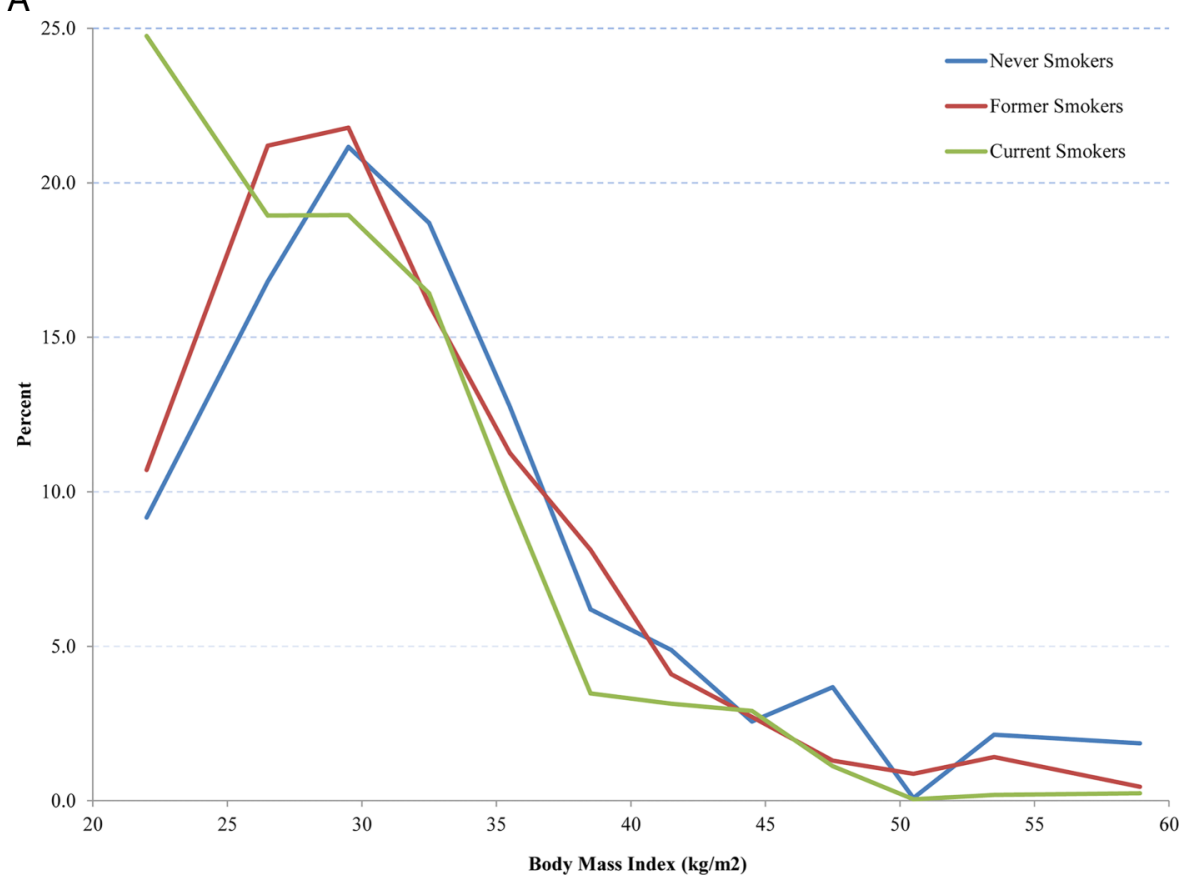

B

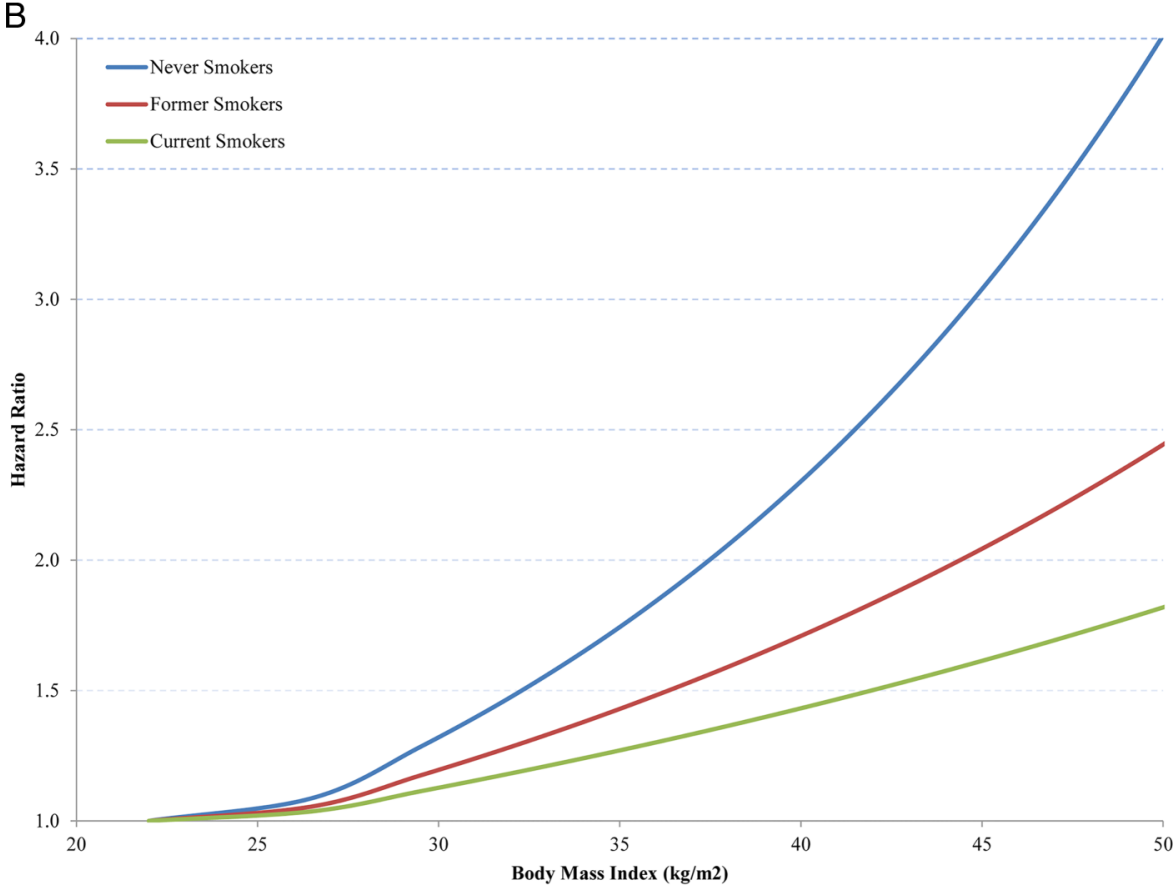

BMI-specific death rates but had the BMI distribution of smokers. Second, we used an analogous process of substitution to calculate what the PAF would be for neversmokers if they had the HRs of current smokers while maintaining their own BMI distribution.

We adjusted for unequal probabilities of selection and non-response using sample weights and accounted for the complex survey design of NHANES. ${ }^{24}$ Analyses were performed using STATA V.12 (StataCorp) and variances were estimated with the SVY routine, which uses Taylor series linearisation. This study was based on anonymous secondary data and thus did not require approval from an ethics committee.

\section{RESULTS}

Table 1 describes characteristics of never-smokers, former smokers and current smokers. Although current smokers were numerically the smallest of the three smoking groups, they experienced the largest number of deaths over the follow-up period. Current smokers were less likely to have been obese in the course of life than the other groups and more likely to have had a maximum weight in the normal BMI range of 18.524.9 (also see figure 1A). On the other hand, former smokers were slightly more likely to have been overweight or obese in the course of life than never-smokers. 
Table 2 HRs for mortality from all causes

\begin{tabular}{|c|c|c|c|c|c|c|}
\hline & \multicolumn{2}{|c|}{ Never-smokers } & \multicolumn{2}{|c|}{ Former smokers } & \multicolumn{2}{|c|}{ Current smokers } \\
\hline & HR & $95 \% \mathrm{Cl}$ & HR & $95 \% \mathrm{Cl}$ & HR & $95 \% \mathrm{Cl}$ \\
\hline \multicolumn{7}{|l|}{ Sex } \\
\hline Women & 1.000 & & 1.000 & & 1.000 & \\
\hline Men & 1.135 & 0.827 to 1.557 & 1.320 & 0.981 to 1.775 & 1.195 & 0.928 to 1.540 \\
\hline \multicolumn{7}{|l|}{ Race/ethnicity } \\
\hline Other & 1.000 & & 1.000 & & 1.000 & \\
\hline Hispanic & 1.058 & 0.676 to 1.656 & 0.857 & 0.544 to 1.351 & 0.953 & 0.558 to 1.628 \\
\hline Non-Hispanic black & $1.512^{*}$ & 1.066 to 2.145 & $1.839^{\star \star \star}$ & 1.334 to 2.536 & $1.513^{\star *}$ & 1.190 to 1.923 \\
\hline \multicolumn{7}{|l|}{ Education level } \\
\hline Less than high school & 1.000 & & 1.000 & & 1.000 & \\
\hline High school & 0.785 & 0.543 to 1.134 & 1.172 & 0.803 to 1.712 & 0.875 & 0.666 to 1.149 \\
\hline More than high school & $0.539^{\star}$ & 0.334 to 0.868 & 1.012 & 0.728 to 1.407 & $0.693^{\star *}$ & 0.546 to 0.881 \\
\hline \multicolumn{7}{|l|}{ Smoking intensity } \\
\hline 0 to $<1$ & & & 1.000 & & 1.000 & \\
\hline 1 to $<2$ & & & 1.002 & 0.738 to 1.361 & 1.251 & 0.922 to 1.699 \\
\hline$\geq 2$ & & & $1.471^{*}$ & 1.049 to 2.064 & 1.383 & 0.951 to 2.013 \\
\hline BMI-25 & $1.057^{\star \star \star}$ & 1.033 to 1.082 & $1.036^{\star \star}$ & 1.015 to 1.059 & 1.024 & 0.997 to 1.052 \\
\hline \multicolumn{7}{|c|}{$\begin{array}{l}\text { *** } \mathrm{p}<0.001 ;{ }^{* *} \mathrm{p}<0.01 ;{ }^{*} \mathrm{p}<0.05 \text {. } \\
\text { Never-smokers are defined as those having smoked less than } 100 \text { cigarettes in their lifetime. The sample includes persons ages } 50-74 \text {. Entry } \\
\text { years are } 1988-2004 \text { with mortality follow-up through } 2006 \text {. HRs are derived from Cox proportional hazards models that adjust for gender, } \\
\text { race/ethnicity (non-Hispanic black, Hispanic, other) and educational attainment (less than high school, high school, some college or greater). } \\
\text { Age is specified as analysis time. BMl-25 is calculated by subtracting } 25 \text { from each person's maximum BMI. Individuals with BMI values } \\
\text { between } 18.5 \text { and } 25 \mathrm{~kg} / \mathrm{m}^{2} \text { constitute the reference category and are assigned a value of } 0 \text {. All estimates are weighted and account for } \\
\text { complex survey design. Sources: National Health and Nutrition Examination Survey. } \\
\text { BMl, body mass index. }\end{array}$} \\
\hline
\end{tabular}

Table 2 and figure 1B present the estimated HRs among the three smoking groups. The HR associated with a one-unit increment in BMI beyond 25.0 was 1.057 (95\% CI 1.033 to $1.082 ; \mathrm{p}<0.001)$ for never-smokers, $1.036(95 \%$ CI 1.015 to $1.059 ; \mathrm{p}<0.01)$ for former smokers and 1.024 (95\% CI 0.997 to 1.052) for current smokers. Thus, higher levels of BMI are a survival threat among all smoking groups, but the threat is more than twice as great among never-smokers as current smokers, with former smokers intermediate. The predicted

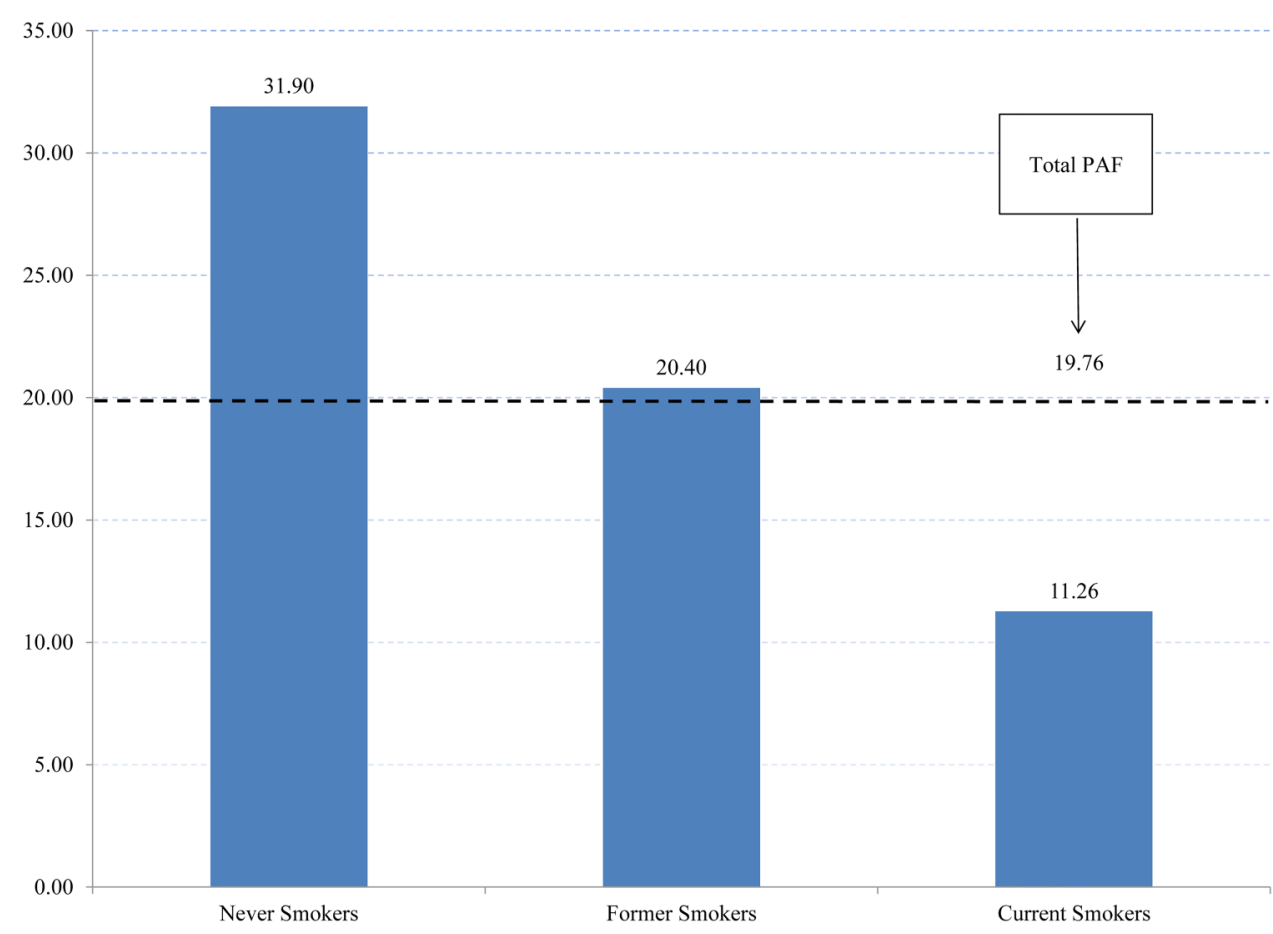

Figure 2 Population attributable fractions (PAFs) for US adults ages 50-74, total and by smoking category. 
hazard ratio associated with a BMI of 40 was $1.057^{15}=2.30$ among never-smokers and $1.024^{15}=1.43$ among current smokers.

Figure 2 shows estimates of the PAF for obesity among the three smoking groups based on equation 1 . It uses the HRs associated with obesity that are shown in table 2, in combination with the actual distribution of deaths by BMI in three-unit wide categories of BMI. Among neversmokers, $31.9 \%$ of deaths in this cohort were attributable to high BMI. Among current smokers, the proportion was only $11.3 \%$. Former smokers were located about halfway between the other two groups at $20.4 \%$. The PAF for the entire population is the death-weighted mean of these figures, or $19.8 \%$.

Why is the fraction of deaths attributable to obesity lower among current smokers? One reason is that the BMI distribution of current smokers is shifted to the left relative to that of never-smokers. If the BMI distribution of current smokers were combined with the relative risks of never-smokers, table 3 shows that the PAF for neversmokers would be $29.9 \%$, compared with its actual value of $31.9 \%$. Thus, of the original difference in PAFs of 20.6 percentage points between never-smokers and current smokers, approximately 2.0 percentage points, or $10 \%$, would be eliminated if never-smokers had the same BMI distribution as current smokers. If the relative risks for current smokers were combined with the BMI distribution of never-smokers, the PAF would be $14.0 \%$, a reduction of 18.0 percentage points compared with the original PAF of never-smokers of $31.9 \%$. This reduction represents $87 \%$ of the original difference in PAFs between the groups (note that the two hypothetical changes add to $97 \%$ rather than $100 \%$ of the original difference because of interactions between the two factors). Thus, these two exercises are consistent in showing that the low relative risks associated with BMI among current smokers are the dominant reason why their PAF is far below that of never-smokers.

\section{DISCUSSION}

It is clear that current smokers have a much lower fraction of deaths attributable to obesity than those who never smoked. It is also clear that the principal source of this difference is that the relative risks associated with obesity are much lower among current smokers than among never-smokers.

One explanation of the lower relative risks among smokers is that competing risks of death are much more prominent among them. Another explanation is that residual confounding by smoking is biasing downwards the relative risks among smokers. However, we introduced detailed information on smoking intensity among current and former smokers into the mortality models, reducing the likelihood that residual confounding is the principal explanation for the lower relative risks among smokers.

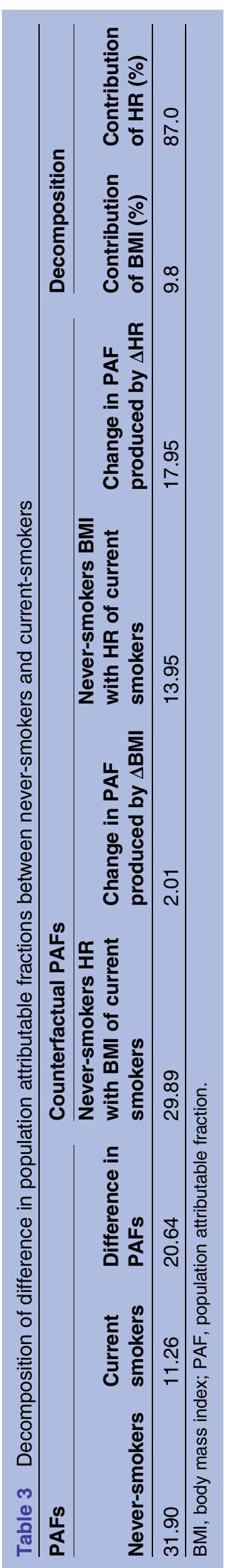


Is the disparity between their PAFs consistent with the mortality risk from smoking itself? Two studies based on data from the National Health Interview Survey and the NHANES estimated mortality risks of smoking in the range of 2.8-3.2 compared with never-smokers. ${ }^{25}{ }^{26}$ If the risk of death of current smokers relative to neversmokers was approximately 3 , then approximately two-thirds of deaths among smokers would be attributable to smoking itself. That leaves only the remaining one-third of deaths to be attributable to obesity and other factors. As a result, the PAF for obesity would be approximately one-third as great for smokers as for never-smokers. In fact, the PAFs for the two groups of $32.0 \%$ and $11.3 \%$ correspond closely to that expectation. The online supplementary appendix includes a more precise illustration of how the proportion of deaths attributable to one exposure should be expected to change when a new exposure is added.

A similar correspondence also prevails among former smokers. The risk of death among former smokers relative to never-smokers is approximately $1.5 .{ }^{26}{ }^{27}$ So about one-third of the deaths among former smokers are attributable to smoking. If the remaining two-thirds had the same PAF as never-smokers, then the PAF among former smokers would be about $0.67 \times 0.32=0.21$, similar to its actual value.

The implication of these findings is that when the PAF for obesity is calculated by excluding groups that are subject to other very significant health risks-not only smokers but also people with diagnosed illnesses or health impairments and very old people-then the attributable fraction will increase. When such exclusions are extensive, they can raise the estimated attributable fraction for obesity well above that pertaining to the population as a whole.

We believe that the strategy pursued in this paper provides a useful approach to dealing with this dilemma. We exclude no one from the attributable risk estimation, so that it pertains to the population as a whole, including sick people and smokers. On the other hand, we use an indicator of obesity, an individual's maximum BMI, which pertains to the life cycle rather than simply to baseline circumstances. An advantage of this indicator is that it has the potential to capture the effects of past obesity status. Also, health problems that may have reduced weight at baseline should have a smaller impact on an individual's maximum lifetime BMI. As a result, the use of maximum BMI should produce less bias in estimating the mortality effects of obesity.

A potential weakness of the paper is the possibility of error in self-reported maximum weight. However, prior studies suggest self-reported past weight is highly correlated with measured weight. ${ }^{28-31}$ Furthermore, maximum weight may be identified more accurately than weight at a specified earlier age (or point in time) since it does not require establishing a correspondence between one's age and one's weight trajectory. Distortions in estimates of the association between obesity and mortality are much smaller when a continuous, linear version of BMI is employed, as in this paper, rather than a categorical version. ${ }^{32}$

The estimated fraction of deaths attributable to obesity is higher than most previous estimates in the USA. $^{7}{ }^{11}$ Prior studies suggest that the association between obesity and mortality declines with age ${ }^{33}$ thus exclusion of older individuals from the sample may be partly responsible for these findings. A second reason is that we use maximum BMI rather than baseline BMI as our indicator of adiposity. The relative risks associated with maximum BMI are substantially greater than those associated with baseline BMI. ${ }^{15}$ We believe that the relative risks that we use are a more accurate representation of the hazards of adiposity than those associated with baseline BMI because maximum BMI better captures risks associated with past obesity status and is less affected by reverse causality.

The higher fraction of deaths attributable to obesity among never-smokers has implications for the set of future death risks facing Americans. Declines in smoking that have already occurred and that may keep occurring are likely to increase the proportion of deaths attributable to obesity. In the extreme, if no one ever smoked we could anticipate that the proportion of death attributable to obesity in the age interval 50-74 would rise from $19.8 \%$, the value for the contemporary US population, to something closer to $31.9 \%$, the PAF for contemporary never-smokers.

In conclusion, the proportion of deaths attributable to obesity among US adults ages $50-74$ is nearly three times as high among never-smokers as among current smokers. The principal reason for this discrepancy is that current smokers have a lower relative risk of death associated with obesity than non-smokers. Such a reduction is consistent with the fact that smokers are subject to a major risk that is 'competing' with obesity and that is itself responsible for many deaths. Former smokers have a PAF that is roughly halfway between that of current smokers and that of never-smokers.

Acknowledgements The authors thank Irma T Elo, Doug Ewbank, Neil K Mehta and Lucia Tiererova for their comments and suggestions.

Contributors AS and SHP contributed to all aspects of this article, including conceptualisation, data analysis and writing.

Funding This project was supported by the National Institute on Aging [R01AG040212].

Disclaimer The content is solely the responsibility of the authors and does not necessarily represent the official views of the National Institutes on Aging or the National Institutes of Health.

Competing interests None declared.

Provenance and peer review Not commissioned; externally peer reviewed.

Data sharing statement No additional data are available.

Open Access This is an Open Access article distributed in accordance with the Creative Commons Attribution Non Commercial (CC BY-NC 4.0) license, which permits others to distribute, remix, adapt, build upon this work noncommercially, and license their derivative works on different terms, provided the original work is properly cited and the use is non-commercial. See: http:// creativecommons.org/licenses/by-nc/4.0/ 


\section{REFERENCES}

1. Murray CJL, Abraham J, Ali MK, et al. U.S. Burden of Disease Collaborators. The state of US health, 1990-2010: Burden of diseases, injuries, and risk factors. JAMA 2013;310:591-608.

2. Allison $\mathrm{D}$, Fontaine $\mathrm{K}$, Manson $\mathrm{J}$, et al. Annual deaths attributable to obesity in the United States. JAMA 1999;282:1530.

3. Calle EE, Rodriguez C, Walker-Thurmond K, et al. Overweight, obesity, and mortality from cancer in a prospectively studied cohort of US adults. N Engl J Med 2003;348:1625-38.

4. Mokdad AH, Marks JS, Stroup DF, et al. Actual causes of death in the United States, 2000. JAMA 2004;291:1238-45.

5. Flegal KM, Graubard BI, Williamson DF, et al. Impact of smoking and preexisting illness on estimates of the fractions of deaths associated with underweight, overweight, and obesity in the US population. Am J Epidemiol 2007;166:975-82.

6. Berrington de Gonzalez A, Hartge P, Cerhan JR, et al. Body-mass index and mortality among 1.46 million White adults. $N$ Engl $\mathrm{J}$ Med 2010;363:2211-19

7. Flegal KM. Bias in calculation of attributable fractions using relative risks from nonsmokers only. Epidemiology 2014;25:913-16.

8. Stokes A. Body-mass index and mortality among white adults. N Engl J Med 2011;364:781-3.

9. Audrain-McGovern J, Benowitz NL. Cigarette smoking, nicotine, and body weight. Clin Pharmacol Ther 2011;90:164-8.

10. Calle EE, Thun MJ, Petrelli JM, et al. Body-mass index and mortality in a prospective cohort of U.S. adults. $N$ Engl J Med 1999;341:1097-105.

11. Koster A, Leitzmann M. The combined relations of adiposity and smoking on mortality. Am J Clin Nutr 2008;88:1206-12.

12. Ma J, Jemal A, Flanders WD, et al. Joint association of adiposity and smoking with mortality among U.S. adults. Prev Med (Baltim) 2013;56:178-84.

13. van Dam R, Li T, Spiegelman D, et al. Combined impact of lifestyle factors on mortality: prospective cohort study in US women. BMJ 2008;337:a1440.

14. Whitlock G, Lewington S, Sherliker P, et al. Prospective Studies Collaboration. Body-mass index and cause-specific mortality in 900,000 adults: collaborative analyses of 57 prospective studies. Lancet 2009;373:1083-96.

15. Stokes A. Using maximum weight to redefine body mass index categories in studies of the mortality risks of obesity. Popul Health Metr 2014;12:6.

16. Mehta NK, Stenholm S, Elo IT, et al. Weight histories and mortality among Finnish adults: the role of duration and peak body mass index. Epidemiology 2014;25:707-10.

17. National Center for Health Statistics. Plan and operation of the third National Health and Nutrition Examination Survey, 1988-94. Series 1 : programs and collection procedures. Vital Health Stat 1994;1:1-407.
18. Zipf G, Chiappa M, Porter KS, et al. National Health and Nutrition Examination Survey: plan and operations, 1999-2010. Vital Health Stat 2010;1:1-37.

19. National Center for Health Statistics. Office of Analysis and Epidemiology. The Third National Health and Nutrition Examination Survey (NHANES III) Linked Mortality File, mortality follow-up through 2006: matching methodology. Hyattsville, MD, 2009.

20. Abdullah A, Wolfe R, Stoelwinder JU, et al. The number of years lived with obesity and the risk of all-cause and cause-specific mortality. Int J Epidemiol 2011;40:985-996.

21. Preston SH, Mehta NK, Stokes A. Modeling obesity histories in cohort analyses of health and mortality. Epidemiology 2013;24:158-66.

22. Joshy G, Korda RJ, Bauman A, et al. Investigation of methodologica factors potentially underlying the apparently paradoxical findings on body mass index and all-cause mortality. PLOS ONE 2014;9: e88641.

23. Benichou J. A review of adjusted estimators of attributable risk. Stat Methods Med Res 2001;10:195-216.

24. Johnson C, Paulose-Ram R, Ogden CL, et al. National Health and Nutrition Examination Survey: analytic guidelines, 1999-2010. National Center for Health Statistics. Vital Health Stat 2013;1:1-24.

25. Jha P, Ramasundarahettige C, Landsman V, et al. 21st-century hazards of smoking and benefits of cessation in the United States. N Engl J Med 2013;368:341-50.

26. Thun MJ, Carter BD, Feskanich D, et al. 50-year trends in smoking-related mortality in the United States. N Engl J Med 2013;368:351-64

27. Mehta N, Preston S. Continued increases in the relative risk of death from smoking. Am J Public Health 2012;102:2181-6.

28. Casey A, Dwyer T, Berkey C, et al. Long-term memory of body weight and past weight satisfaction: a longitudinal follow-up study. Am J Clin 1991;53:1493-8.

29. Perry G, Byers T, Mokdad A, et al. The validity of self-reports of past body weights by US adults. Epidemiology 1995;6:61-6.

30. Stevens J, Keil JE, Waid LR, et al. Accuracy of current, 4-year, and 28-year self-reported body weight in an elderly population. $A m \mathrm{~J}$ Epidemiol 1990;132:1156-63.

31. Rhoads G, Kagan A. The relation of coronary disease, stroke, and mortality to weight in youth and in middle age. Lancet 1983;321:492-5.

32. Preston SH, Fishman E, Stokes A. Effects of categorization and self-report bias on estimates of the association between obesity and mortality. Ann Epidemiol 2015;25:907-11.e2.

33. Wang Z. Age and the impact of obesity on mortality. Am J Public Health 2014;104:3-6. 